\title{
English Language Apprehension and the Reading-Writing Competence of Students
}

\author{
Ronnel D. Baful, Chester M. Derequito \\ College of Teacher Education, Laguna State Polytechnic University San Pablo City, Laguna, 4000 \\ Philippines \\ Email Address:_chester.derequito@lspu.edu.ph
}

\begin{abstract}
:
This research study aimed to explore the association between undergraduates' English language apprehension and their reading-writing ability. A descriptive-correlation design was used, with survey questionnaires and tests disseminated using Google forms. The researcher employed a questionnaire adapted and modified from MacIntyre and Gardner (1994) to determine the level of English language apprehension. It comprises three components of learning processes: input, processing, and output stage. The data was then quantified and evaluated using mean and standard deviation for English language apprehension, frequency, and percentage for reading-writing skills. Pearson product-moment correlation was used to examine the relationship between apprehension and reading and writing abilities. The undergraduate students reported a neutral level of apprehension in the second language and were competent in reading and writing. The study's findings imply that English language apprehension has a significant association with students' readingwriting skills. Furthermore, a negative correlation is found on apprehension level experienced in the input stage of learning and applied reading comprehension and processing anxiety and writing fluency.
\end{abstract}

Keywords-English language apprehension, reading skills, reading-writing competence, second language anxiety, writing skills

\section{Introduction:}

Language proficiency has a significant impact on society. It ensures the credibility of the educational system and the populace's ability to function in a modern, English-speaking world. While the Philippines remains a popular destination for English learners due to the affordable price and quality of available programs for the English language, Jugo (2020) observes a disturbing trend of diminishing English proficiency among teachers and learners. Proficiency levels have been gradually falling, negatively impacting Filipino graduates.

The EF Proficiency Index website reported the Philippines declination in the English proficiency index in 2020. Based on the data, the country fell seven places in the global rankings. The Philippines is ranked 27th in the 2020 report, and statistics show that learners' English competence is declining. In 2016, the country was ranked 13th worldwide but dropped to 15th, 14th, and 20th from 2016 to 2018. Concerned about declining competency, the Department of Education (DepEd) launched fundamental modifications in the K12 educational program through "Sulong EduKalidad."

Berowa (2018), Kabigting (2020), and Jugo (2020) discovered that language anxiety is a powerful predictor of language competence in recent research of Filipino learners. Gardner and MacIntyre (1994) expounded that anxiety is a learner's experience of dread and uncertainty when speaking in a foreign language. It has a severe impact on output production in all macro skills, making acquisition impossible or difficult. A high level of anxiety also impacts a learner's achievement, most notably gaining a higher grade or score on a test. 
With these findings, the researcher intended to investigate foreign language apprehension in the Philippines and identify the underlying elements contributing to such apprehension in the Filipino context.

In the Filipino context, Lucas et al. (2011), Gomari and Lucas (2013), Macayan (2018), Berowa (2018), Kabigting (2020), and Jugo (2020) used similar measures in identifying the learner's apprehension level. Based on their findings, anxiety has varying effects on language achievement. For example, some learners keep a moderate or neutral level of English language apprehension to motivate themselves to do better. Some students experience higher anxiety levels in speaking activities, including recitation, reporting, and communicating with their second language teachers. Further research in different contexts was done because of these studies. Finally, while some are well-established, others are still up for debate.

A recent study on the psychological consequence of the COVID-19 pandemic conducted by Tee et al. (2020) in the Philippines revealed that learners indicated a moderate-to-severe pandemic effect on their mental health. The Philippine-imposed house confinement and lockdown are also linked to depression, anxiety, and stress symptoms. This study focused on Laguna State Polytechnic University-San Pablo Campus in Barangay Del Remedio, San Pablo City, Laguna. The university is also under the distance learning system education through online means, with students limited to their homes where such confinement may add to psychological anxiety and hinder learners' ability to perform successfully in the second language. The researcher sought to determine whether concerns about the English language exist among second-year English majors and to assess their reading and writing abilities.

\section{Conceptual Frame Work:}

MacIntyre and Gardner (1994) introduced the Input, Processing, and Output Anxiety Scale in foreign language anxiety research. It is formulated from Tobias' (1986)three stages of cognitive learning. Anxiety is a dynamic threshold that hinders second language acquisition. Input anxiety is a student's apprehension when introduced to new sentences, phrases, or words in the second language. It is primarily concerned with the encoding of external inputs. When a student is performing a task, they experience processing anxiety. They attempt to organize and save the information received from an external stimulus. Finally, output anxiety refers to learners' stress when demonstrating their knowledge or competence on previously taught subjects. It is concerned with an individual's ultimate output based on the previous two learning stages.

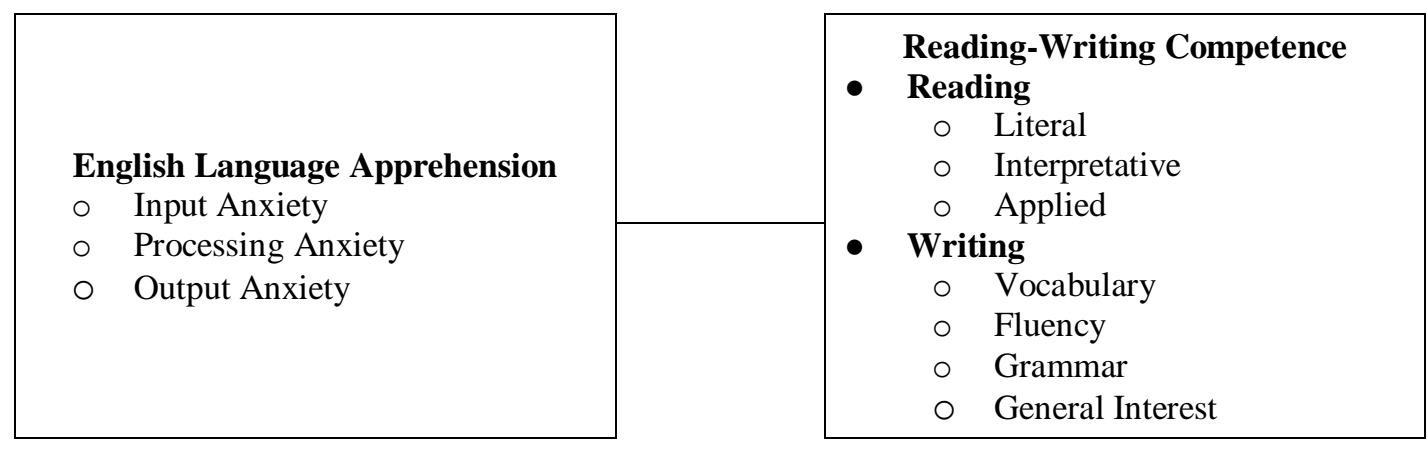

Figure 1. Research Paradigm

Shanahan and Lomax (1986) suggested three models of reading and writing skills. One of them is the interactive model, where it is the first to propose that reading inspires writing and that writing influences reading. Ruddell (2001) proposed the Reciprocal Questioning paradigm based on Herber's (1978) reading comprehension levels. When a student engages with a text, he claims that reading has three components. There are three levels: literal, interpretive, and applied. The literal level refers to the learner's cognitive abilities, which are associated with knowledge and comprehension. At the interpretive level, the learner is asked to read between the lines. The applied level refers to the learners' ability to use higher-order thinking skills.

Argaman and Abu-Rabia (2002) formulated four unique writing components to test their responders' writing ability: vocabulary, fluency, grammar, and general interest. The number of 'difficult' words utilized by the learner is referred to as vocabulary. The degree to which the student's written language conveyed fluidity is referred to as writing fluency. Grammar focused on tenses, verb inflection based on persons, tenses, and 
other elements. Originality, drawing the reader in, and writing a readable text are all signs of general interest. Overall, writing proficiency can be guided with these components, as it identifies the learner's abilities.

\section{Literaure Review:}

Several researchers generated inconclusive results and disagreed with the sub categorization of language anxiety. The inquiry into the association between anxiety and performance continues, with variable and perplexing conclusions. Foreign language anxiety has been predicted and proven by previous studies to impact an individual's academic progress. It functions as a filter, indicating whether the learner will receive information if the threshold is decreased or raised. It is self-regulated and arouses depending on the learner's environment or condition. As a result, performance is influenced by worry because it predicts whether learners can comprehend.

Anxiety is an outcome of language acquisition rather than an origin. Self-related cognition is regarded as a negative role that diverts attention away from cognitive processes. The higher a learner's stress level, the more likely they will not retain the material. Negative and irrelevant thoughts impede learning. Even if learners have sufficient knowledge, encoding will be hampered if they doubt themselves, resulting in reduced input intake and a negative influence on expected output. The processes are interconnected. As a result, anxiousness is transferred. An increase in anxiety at an earlier stage will affect the following functions.

Alemi et al. (2011) state that the continuing utilization of a second language inside and outside the classroom differs depending on the various learning aspects such as linguistic, communicative, social, and psychological. The use of language is entirely contingent on the situation, as demonstrated by an individual speaking or reading depending on the situation. When the findings revealed that higher adept learners were less talkative in a class than those with less experience, they made a surprising discovery. Furthermore, speaking abilities have no tangible link with language anxiety. This demonstrates that fear does not affect the learner's performance.

Liu and Huang (2010) postulate that more studies on anxiety must be done in varied settings with learners from various backgrounds to understand it better. Students said they do not feel apprehensive in an English lesson, are not afraid of unfavorable evaluations, and are not intimidated by speaking and assessment tasks. Most of them showed moderate to high levels of motivation to learn. They expressed a strong desire to learn foreign languages and communicate with individuals from other cultures. Motivation and anxiety were also found to be strongly adversely associated, according to the findings. Anxious learners are less motivated, but they are motivated when external stimuli, such as requirements, are present.

Legac (2012) stressed that bilingual learners are more efficient language learners than monolingual persons. This is because they are exposed to another language regularly. Bilingualism is thus a helpful element in acquiring a second language. Furthermore, bilinguals have lower levels of linguistic anxiety than monolinguals. Legac (2012) discovered that speaking achievement relates to processing anxiety using the same model provided by MacIntyre and Gardner (1994). Furthermore, worry is negatively associated with speaking achievement. According to the study, the learning environment should be favorable to teaching new languages to the learner.

Jafarigohar and Behrooznia (2012) state that teachers should encourage a cooperative learning environment where stresses are considered and minimized to support good knowledge transfer. They also discovered a link between students' foreign language anxiety and their reading comprehension. Although age does not determine anxiety, females experience it at a higher rate than males. Anxiety can also be viewed as a motivator, as shown to improve an individual's verbal skills. The educator, like a doctor, must adjust the dose so that learning occurs flawlessly.

According to Salehi and Marefat (2014), foreign language fear impairs learning. There is a significant association between linguistic and anxiety in assessment and a substantial negative correlation between anxiety and academic proficiency. The anxious student tends to be nervous about tests, which has a detrimental impact on their academic performance. A pleasant environment promotes the transfer of knowledge. Training and seminars can provide various options, and this knowledge of dealing with stress and anxiety can be passed on to students. Anxiety is a negative predictor; thus, a positive emotional element, such as motivation or boosting confidence inside the classroom, might lessen it. 
Trebits (2014) claimed that output anxiety has a considerable and robust link with students' speaking skills. The learners' output is similarly affected by input and processing anxiety. Findings suggested that anxiety is present at various phases of learning and affects learning depending on the task and medium. Language production progresses with each level. As a result, the task's output depends on the stage of anxiety experienced. The number of cognitive tasks influences the level of expertise. A written assignment, for example, has a considerable negative effect on processing and output anxiety. However, if kids perform well in language, anxiety is avoided, provided they can comprehend and produce output depending on the input. Despite having a high level of skill, anxious pupils dedicate less public attention to encoding a piece of information.

Language anxiety and reading achievement were found to be significantly different by Mohammadpur and Ghafournia (2015). Even though they were English majors, students with high and intermediate reading levels showed much less reading anxiety than students with low reading levels. Reading level has a negative relationship with reading anxiety. The researchers proposed that language teachers and curriculum developers reduce practical elements to increase reading ability. To increase motivation and self-confidence, learners must be exposed to comprehensible input and culturally relevant literature.

Al-Khasawneh (2016) investigated the relationship between a student's grade level and anxiety in the second language. The respondents indicated a moderate worry and uncertainty in communication and English lessons and a dread of unfavorable assessment and exam anxiety. Teachers, as educators, appear to have an important influence on second language learning. They can function as a moderator to reduce worry and augment motivation to improve their mood and interest. Communication apprehension had a more significant impact on learning, and it may be reduced by good instruction and encoding in information transfer. According to the findings, the student's level does not predict worries because no significant association is identified.

Yassin (2017) expounded that the level of second language anxiety lessens with expertise in the learning environment. According to the data, first-year students are more anxious than second, third, and fourth-year students. The high level could be attributed to their continual exposure to years of studying the second language. Anxiety may be helped using one's mother tongue.

Sabbah (2018) states that anxiety is a critical affective element that has a significant and detrimental impact on second language acquisition. It forecasts one's academic development, and some components are required to push a person to work harder. Policies, regulations, faculty, and administrative personnel of an institution are all identified as stresses. To lessen anxiety to an acceptable level, all of this must work together and present ideologies to alleviate the learners' stress. Students reported a notable level of second language anxiety when it came to testing assessment concepts. They are concerned that the grades earned due to the projects, requirements, and examinations would negatively impact their performance. They also exhibit anxiety when undertaking academic activities written by other instructors because they are not adequately orientated or trained differently. They also indicated that they are afraid of failing at the start of the semester since they do not fully understand what will happen in their journey on their chosen courses.

Teimouri (2019) confirms linguistic anxiety's harmful influence on the learning process. Furthermore, worry predicts listening performance more than speaking performance. Anxiety comes when they are under time constraints and are expected to absorb and decipher the interlocutor's message in the allotted time. Such stress impairs their ability to read and understand the material, thereby limiting their language skills. Due to their high level of apprehension, children may not stop a discourse from asking for repetition or clarification. In contrast to listening, students can read the information at their own pace, reread it to understand the context, and effectively complete thought in response to the text. Finally, trait anxiety has less of an impact on anxiety when linguistic anxiety transforms into situation-specific worry.

Anggraeny et al. (2020) expounded that English anxiety predicts and impacts pupils in a class. Worry occurs when people attempt to comprehend the output of external stimuli. They fail to take it because they lack a suitable schema, resulting in anxiety that impedes information transfer. Students indicated that they could not talk in the target language and convey or communicate their thoughts when called upon in class. When they converse with natural speakers of the language, their anxiety level rises. As a result, students frequently skip speaking class because this component stresses them out. Aside from that, pupils struggle with speaking, notably a lack of vocabulary, grammatical errors, and pronunciation. They reported a low level of nervousness if they prepared by memorizing the contents or being knowledgeable about the issue. 
Oruc and Demirci (2020) postulate that engagement predicts English language achievement. When it is engaged, the effect of linguistic anxiety on performance is reduced to some extent. As a result, participation in a second language classroom does not simply predict foreign language anxiety. Other elements may have an impact on their relationship. Anxiety harms student achievement. It lowers the level of participation and makes collecting information more difficult. The engagement has a favorable consequence on language achievement; hence, the degree of performance is reduced when it is reduced.

According to Lucas et al. (2011), learners may develop language anxiety due to their unpleasant experience, resulting in a "fear of losing face" in the learning setting. Learners reported having sufficient information and learning techniques to cope with language anxiety. Vocabulary is one of the most regularly employed methods. It functions as a learning framework, decoding inputs and producing an output enhanced by the schema and newly gained information. With this skill, a learner can absorb a language in a more manageable and effective manner. When their teachers or peers judge their performance in the target language, learners suffer high anxiety levels.

Ariola (2011) discovered that a person lacking self-confidence does poorly in language, particularly while speaking. Because of its multidimensional nature, anxiety extends beyond the learning environment and into other social contexts. Language anxiety is caused mainly by adverse learning difficulties, self-related cognitions, interlocutors, dread of unfavorable criticism, and self-perception. Language anxiety, caused by a lack of experience and practice, is an affective filter that affects language performance. The interviewees have little exposure to it because they frequently use Taglish while communicating with peers or superiors. Language anxiety arises because of their inability to communicate in a second language. The highest anxiousness is felt when speaking. Even if the Filipino respondents are fluent, many are nervous when speaking in public. The data also validated the recent trend of utilizing Taglish in business transactions and communication. Because of its nature, the students claimed that they are more at ease with it and are less likely to be graded on proper norms and grammar.

Gomari and Lucas (2013) wanted to know if learners are driven to learn, if they have language anxiety and if thetwo affective characteristics are related. According to the findings, the learner is not intrinsically or extrinsically motivated to study English. There is also a moderate level of language anxiety. However, data reveals a strong and inverse relationship between motivation and anxiety among students. Furthermore, pupils reported being intrinsically motivated to learn. They learn to master it, exceed their expectations, and achieve personal objectives such as speaking. Motivation and second language anxiety both have an impact on one another and are intertwined. A high degree of motivation implies a lower level of anxiety, whereas a lower amount of motivation suggests high anxiety.

Macayan (2018) mentioned that anxiety, uncertainty, and nervousness are still prevalent in the twenty-first century. The researcher wanted to look at how this phenomenon affected foreign language writing and speaking abilities. According to the data, there is a significant association between both speaking fears. When asked to speak, students reported feeling extremely anxious. Anxious students are less likely to perform well in public speaking assignments. Learners are eager because they are in the presence of their peers, whom they fear will pass judgment and criticism, as well as their instructor, whom they hope will provide favorable feedback. In addition, students indicated a high level of anxiety when writing because they are concerned about how they will be evaluated. Since writing, learners can recheck their work because they fear being judged, resulting in sound written output.

Berowa (2018) states that Filipino students have a neutral level of English language anxiety. They can preserve their self-esteem. It does not prevent individuals from becoming competent in the second language, nor does it keep them relaxed or overly nervous; it is just the perfect degree. According to the data, respondents indicated a moderate level of anxiousness. Furthermore, there is no correlation between a student's year level and gender. This is a good indication that the learning environment is favorable and maintains a neutral level of anxiety, indicating that it is beneficial. A moderate level of anxiety is thought to keep learners motivated and working hard. Less anxious students are more likely to admirably on communicative tasks, tests, and assessments. A learning environment can reduce a learner's anxiety. This implies that peers, teachers, and administrators may all help students learn. A reasonable level of anxiety promotes learning by encouraging positive self-cognition and is guided by the learning environment.

Kabigting (2020) discovered that Filipino senior high school pupils had a neutral degree of language anxiety. Furthermore, they are highly excellent English, implying that mild anxiety facilitates second 
language learning. One of the most critical jobs for students is to keep their anxiety at a manageable level to learn more. The moderated group maintains the learners' motivation and self-confidence in understanding input and producing a decent output based on their schema and newly discovered knowledge. Teachers must hold a moderate level of anxiety to prevent students from becoming overly calm while learning. Learners may feel less anxious in the language because they have been exposed to it since childhood. They have been in the process of learning and communicating in English constantly.

Jugo (2020) performed a recent study to understand better the second language anxiety of Filipino undergraduate students. She discovered that speaking activities, correcting language errors, and communicating with native speakers predict language anxiety. A moderate amount of language anxiety is also indicated by activities in writing. Language anxiety is apredictor of proficiency in the second language. Learners display high levels of language anxiety due to various factors, including apprehension about their surroundings. Anxious students outperform those who are not. When it comes to creating output in the target language, they have a wide range of experience. Anxiety prevents students from completing assignments, even if they are well-versed in the subject. Furthermore, Filipino undergraduate education students indicated that worry is primarily a factor in the output stage.

\section{Synthesis}

Based on previous and recent data, it is reasonable to conclude that anxiety is still pervasive in modern culture. As Macayan (2018) pointed out, worry, uncertainty, and anxiousness are still common in the twenty-first century. It is harmful and has a significant and negative impact on language proficiency. Apprehension in the language is detrimental to language learning. It is critical in anticipating learners' skill levels and understanding the dynamics of second language acquisition. When the level of apprehension is high, cognitive processes are hampered. Numerous potential causes or factors have been identified and must be examined as inconsistent socio-cultural differences lead to varying results.

Several gaps in previous and recent studies on foreign language anxiety were also discovered. In the Filipino context, Lucas et al. (2011), Gomari and Lucas (2013), Macayan (2018), Berowa (2018), and Kabigting (2020)used similar measures in identifying the learner's apprehension level. None of them has ever used the Input, Processing, and Output Anxiety Scale. Based on the instrument analysis performed by Onwuegbuzie et al. (2000) and Piniel (2012) and the researcher's pilot test results, the IPOAS scale is suitable for the Philippine setting. The researcher chose the IPOAS scale over the FLCAS to better understand the anxiety felt during the three learning procedures. Most research has focused on output quality while ignoring potential implications in other areas. Finally, the researcher intended to direct this concern on Filipino undergraduate Teacher Education students.

\section{OBJECTIVES OF THE STUDY}

The study's objectives are as follows.

1. What is the students' level of English language apprehension in terms of:

1.1. input anxiety,

1.2. processing anxiety, and

1.3. output anxiety?

2. What is the students' level of reading-writing competence in terms of:

2.1. literal,

2.2. interpretative,

2.3. applied,

2.4. vocabulary,

2.5. fluency,

2.6. grammar, and

2.7. general interest?

3. Is there a significant relationship between students' English language apprehension and their readingwriting competence? 


\section{Methodology:}

\section{Research Design}

The research utilized a descriptive research design. A questionnaire was used to assess language apprehension and a reading-writing competence test to evaluate language performance. A correlational methodology was also used to understand the relationship between English language apprehension and reading-writing proficiency.

\section{Participants}

The researcher surveyed forty-two (42) university students enrolled at Laguna State Polytechnic UniversitySan Pablo Campus in the second semester of the 2020-2021 academic year. The population consists of College of Teacher Education second-year English major students.

\section{Instrumentation}

In this investigation, two instruments were used. The first instrument isaneighteen-item (18) English Language Apprehension Scale Test (ELAST), adapted and modified from MacIntyre and Gardner's (1994) IPOAS, with responses on a Likert scale extending from 5 (Always) to 1 (Never). It has three components of language apprehension. Each six-item scale contained questions that were worded negatively.

Aforty-item (40) Reading-Writing Competency Test (RWCT) was used as the second instrument. A twentyitem (20) test for reading comprehension was given to the respondents. Respondents were asked to write an essay about their most memorable moment during the pandemic to test their writing ability. Based on Argaman and Abu-(2002) Rabia's criteria for writing ability, a rubric directed the written output. The research instrument was validated and pilot tested to establish validity and reliability. To produce a fluid response, the anxiety scale was altered and adapted into the Philippine setting. The word "English "replaced"French and positive statements were transmuted into negative questions. The study's panelists suggested changes to the measures before they were assessed and approved by three subject experts. Following the instrument verification, the researcher altered and made essential changes based on their feedback, comments, and suggestions.

Table 1. Reliability Statistics of the English Language Apprehension Scale Test

\begin{tabular}{|c|c|c|}
\hline Subscale & Number of Items & Cronbach's Alpha \\
\hline Input Anxiety Scale & 6 & 0.756 \\
\hline Processing Anxiety Scale & 6 & 0.719 \\
\hline Output Anxiety Scale & 6 & 0.713 \\
\hline
\end{tabular}

Legend: $0.9 \geq \alpha \geq 0.8=$ Good, $0.8 \geq \alpha \geq 0.7=$ Acceptable, $0.7 \geq \alpha \geq 0.6=$ Questionable, $0.6 \geq \alpha \geq 0.5=$ Poor, $0.5 \geq \alpha=$ Unacceptable

To assess the reliability of the research instrument, the researcher administered the tool to fifteen (15) college students at the same level as the intended respondents. The research instrument was analyzed and determined for each scale's validity for use. It produces thereliability estimates shown in Table 1, which the study's statistician calculated using the SPSS software.According to the Cronbach alpha, all three scales have acceptable internal consistency. As a result, the tool used to assess language apprehension is reliable, valid, and suitable for affective measurements.

The researcher constructed the instrument for measuring reading-writing skills obtained from the 2020 DepEd English Language Proficiency Test. The reading assessment consisted of twenty (20) items dedicated to answering three passages corresponding to the respondents' reading level. Six questions are for the literal and interpretative reading comprehension levels, while eight itemsare for the applied level. The first two levels are multiple-choice; however, the applied level test is dedicated to students' thoughts and responses. The respondents were asked to compose a three-hundred-word (300) essay. It was worth twenty (20) points and was based on the criteria for writing proficiency established by Argaman and Abu-Rabia (2002). Each component, namely vocabulary, fluency, grammar, and general interest, received five points. 


\section{Data Collection Procedure}

An online survey driven by Google Forms was used to collect the data. The intended respondents were emailed a link to the survey questionnaire and assessment after they confirmed their participation. Respondents completed the survey in their spare time. The data collection period lasted eight days. The researcher acknowledged completing the data collection and sent another email to the responders to express his gratitude.A subject expert supported the researcher in reviewing the respondents' writing outputs. The researcher prepared a data matrix based on the results of the reading-writing competence assessment. The research statistician then evaluated the data before the researcher analyzed and concluded the research.

\section{Data Analyses}

The respondents' degree of English language apprehension and reading-writing proficiency was measured using the following statistical techniques.

Mean and standard deviation was utilized to assess the undergraduates' anxiety in the three components of English language apprehension. The respondents' reading-writing competencies were tested using frequency and percentage. The Pearson product-moment correlation technique was used to identify the correlation between language apprehension and the respondent's reading-writing competence.

Table 2. English Language Apprehension Scale

\begin{tabular}{|c|c|}
\hline & \\
\hline Mean & Interpretation \\
\hline $4.31-5.0$ & Very high \\
\hline $3.51-4.30$ & High \\
\hline $2.71-3.50$ & Neutral \\
\hline $1.81-2.70$ & Low \\
\hline Below 1.8 & Very low \\
\hline
\end{tabular}

The scale in Table 2 was used to interpret the respondent's level of English language apprehension. It comprises five average mean ranges, with verbal interpretations ranging from very high to very low anxiety.

Table 3. Reading-Writing Competence Descriptors

\begin{tabular}{|c|c|}
\hline Grading Scale & Descriptor \\
\hline $90-100$ & Outstanding \\
\hline 85-89 & Very Satisfactory \\
\hline $80-84$ & Satisfactory \\
\hline $75-79$ & Fair Satisfactory \\
\hline Below 75 & Did Not Meet Expectation \\
\hline
\end{tabular}

The researcher used the descriptors and remarks indicated in DepEd Order 8, s.2015 entitled Policy Guidelines on Classroom Assessment for the K to 12 Basic Education Program to define the reading-writing competency of the research respondents. It includes competency descriptors ranging from outstanding to did not meet the expectation.

\section{Results and Discussion:}

Table 4. English Language Apprehension in Terms of Input Anxiety

\begin{tabular}{|c|c|c|c|}
\hline Indicators & Mean & SD & Interpretation \\
\hline 1. I am bothered when I cannot understand what the teacher says. & 2.55 & 0.83 & Low \\
\hline 2. It bothers me if my English notes are disorganized before I study them. & 3.15 & 1.12 & Neutral \\
\hline 3. I do not enjoy listening to someone speaking English. & 1.91 & 0.91 & Low \\
\hline 4. I get flustered unless English is spoken very slowly and deliberately. & 3.07 & 0.95 & Neutral \\
\hline $\begin{array}{l}\text { 5. I get upset when I read in English because I must read things again and } \\
\text { again. }\end{array}$ & 2.69 & 1.09 & Neutral \\
\hline
\end{tabular}


6. I get upset when English is spoken too quickly. Average
3.19

2.77
Neutral

Neutral

Table 4 presents the respondents' level of English language apprehension in terms of input anxiety. As per the data, the average mean of their anxiety at this component is 2.77 , with a standard deviation of 0.50 . It follows that learners have a neutral level of English language apprehension during the input stage of learning. According to the findings of Berowa (2018) and Jugo (2020), Filipino learners do not deny anxiety in the second language, but they maintain a neutral level to aid learning. They are self-assured and may only have minor levels of English language fear due to external stimuli and speaking activities. Kabigting (2020) also mentioned that moderated apprehension maintains the learners' motivation and self-confidence in understanding input and producing a decent output based on their schema and newly learned knowledge.

Item 6 has the highest average mean of 3.19 and the verbal meaning of neutral. Learners are concerned when an external stimulus decodes their/its message too swiftly. It is strongly reliant on an individual's memory capacity to store and process the input. Trebits (2014) postulates that learners are more anxious when decoding spoken processes than translating textual modalities. According to Jugo's (2020) results, Filipino learners express a substantial level of anxiety when encoding an external message, and speaking activities are negative predictors. When a language is spoken too quickly and a learner does not fully comprehend it, they may suffer anxiety due to various circumstances. They may be unable to concentrate on the input, which raises the level of the filter. Krashen (1986) states that raising the filter lowers the acquisition of the input. When the input material is decoded too rapidly, the learners experience increased anxiety, and their encoding level is not proportional to the decoding rate.

Item 3 has the lowest average mean of 1.91, indicating a low level of English language apprehension. Students reported a low level of nervousness when listening to someone speaking in English. It suggests that the study respondents like learning English as second language learners and potential second language educators. Mohammadpur and Ghafournia (2015) state that being an English major does not necessarily mean being free from experiencing anxiety. Concerning the findings of the high source of anxiety, learners may feel worried when the language is delivered too quickly, but this does not indicate they reject the English language. As aspiring second language teachers, this is a solid sign that they must be interested in English.

Table 5. English Language Apprehension in Terms of Processing Anxiety

\begin{tabular}{|c|c|c|c|}
\hline Indicators & Mean & SD & Interpretation \\
\hline $\begin{array}{l}\text { 7. Learning new English vocabulary worries me; I cannot acquire it in } \\
\text { time. }\end{array}$ & 2.57 & 0.89 & Low \\
\hline $\begin{array}{l}\text { 8. I am anxious about English because no matter how hard I try, I have } \\
\text { trouble understanding it. }\end{array}$ & 2.24 & 0.73 & Low \\
\hline $\begin{array}{l}\text { 9. The only time I feel comfortable during English tests is when I have had } \\
\text { much time to study. }\end{array}$ & 3.74 & 1.13 & High \\
\hline 10. I feel anxious if the English class seems disorganized. & 4 & 0.83 & High \\
\hline $\begin{array}{l}\text { 11. I am not self-confident in my ability to appreciate the meaning of } \\
\text { English dialogue. }\end{array}$ & 2.33 & 0.79 & Low \\
\hline $\begin{array}{l}\text { 12. I worry when I hear new or unfamiliar words; I am not confident I can } \\
\text { understand them. }\end{array}$ & 3.05 & 0.81 & Neutral \\
\hline Average & 2.99 & 0.42 & Neutral \\
\hline
\end{tabular}

Table 5 depicts the respondent's level of English language apprehension in terms of processing anxiety. The statistics show that the average mean is 2.99 , with a standard deviation of 0.42 . It is perceived as a level of anxiousness that is neither high nor low. It means that learners have a modest level of anxiety during the processing stage of learning. As previously stated, in the context of Filipino learners, pupils maintain a neutral level to retain motivation. It boosts their motivation to achieve better.

Furthermore, the respondents are welcome to participate in understanding and processing tasks using the second language. They have a positive self-concept, and anxiety is primarily influenced by external 
variables such as social or environmental circumstances. High self-cognition in the processing stages indicates the high quality of the knowledge if not disrupted.

Item 10 has the highest average mean of 4, which translates to "high." When the English class appears unorganized, students report feeling anxious. This implies that the learning environment is involved in the learning process. Mohammadpur and Ghafournia (2015) expound that the learning environment increases learners' abilities. Students may experience stress if their mental state is confused by the chaos of their surroundings, preventing them from digesting the input. Ariola (2011) suggests that anxiety spreads beyond the learning environment.

Furthermore, due to the nature of anxiety, it may be present if an external stimulus, such as noise or other disruptors, impacts the learner. Stress caused by the environment interferes with knowledge processing. Most of the time, the environment cannot be regulated for a variety of reasons. Teachers cannot restrict their students in the classroom, or the learning approach or execution is inadequate. This prevents learners from processing input because an external stimulus stresses them or disturbs information transfer.

Item number 8 has the lowest average mean of 2.24, indicating low English language apprehension. Students reported a low level of anxiety when understanding the English language, as expected, given that data from the input stage of learning indicates a high level of interest and enjoyment of second language learners. Second-year English majors can understand the English language. They are the country's future instructors, and their positive self-concept in using the English language will serve them well. High-performing educators can help students improve their skills and lessen their anxiety during the learning process. Kabilan et al. (2010) stress that a complete understanding of the language improves students' performance, expands their knowledge, and develops insights. Students are more likely to understand input if they are enthusiastic about taking it in and driven to learn it. Disorganization causes negative emotions such as unease, dread, and anxiety. Furthermore, a conducive learning environment makes learning more efficient and effective, and proper knowledge, belief, or insights increases one's self-cognition in the second language.

Table 6 English Language Apprehension in Terms of Output Anxiety

\begin{tabular}{|l|c|c|c|}
\hline \multicolumn{1}{|c|}{ Indicators } & Mean & SD & Interpretation \\
\hline \multicolumn{1}{|c|}{} & 3.12 & 0.83 & Neutral \\
\hline $\begin{array}{l}\text { 13. I feel tense when I have to speak in English. } \\
\text { know in a conversation. }\end{array}$ & 2.52 & 0.80 & Low \\
\hline $\begin{array}{l}\text { 14. I don't feel confident that I can easily use the English vocabulary that I } \\
\text { 15. I may know the proper English expression, but it will not come out } \\
\text { when I am nervous. }\end{array}$ & 3.71 & 0.99 \\
\hline $\begin{array}{l}\text { 16. I get upset when I know how to communicate something in English, but } \\
\text { I cannot verbalize it. }\end{array}$ & 3.79 & 0.98 & High \\
\hline 17. I get nervous when writing something for my English class. & 2.64 & 1.10 & Neutral \\
\hline $\begin{array}{l}\text { 18. When I become anxious during an English test, I cannot remember } \\
\text { anything I studied. }\end{array}$ & 3.19 & 1.11 & Neutral \\
\hline Average & $\mathbf{3 . 1 6}$ & $\mathbf{0 . 6 0}$ & Neutral \\
\hline
\end{tabular}

Table 6 presents the respondents' level of English language apprehension regarding anxiety experienced during the learning process. Based on the current table, the pupils have a neutral degree of language anxiety, with an average mean of 3.16 and 0.60 standard deviations. In terms of output anxiety, learners reported a moderate amount of anxiety. These findings show that a significant number of pupils are anxious in their learning environment. It might be their classmates or incorrect correction from their teachers or professors that they are afraid of. It suggests that, despite their ability in the second language, most Filipino learners cannot ultimately facilitate it in terms of output due to their fear of the environment. This fear prevents them from making a sound output based on the input they encoded and processed earlier in the learning process.

Item 16 has the highest average mean of 3.79, indicating a high verbal interpretation. Students stated that they get irritated when communicating in English but cannot express their feelings verbally. Many underlying elements, such as their self-cognition and contextual influences, can be explored in this topic. Harmful levels at this component may affect their performance, depending on the context. Jugo's (2020) research also indicates that Filipino learners experience high levels of apprehension in the output process of 
learning. This is because they are afraid of being corrected or judged by their peers or educators. Such dread results in negative self-cognition, which reduces output quality and, as a result, proficiency. Even if they have the necessary knowledge, they cannot deliver a sound output if nervous. They doubt themselves because they are afraid of their surroundings. As per Macayan's (2018) Filipino respondents, the social component is vital in learning and causes subjective sensations when conveying their opinions. This could be because their presence raises their anxiety, and they are afraid of being scrutinized or condemned by their peers or instructors. Most students strive to make a positive impression, limiting their ability to produce better results since they are clouded by negative self-perception.

Item 14 has the lowest mean score of 2.52 out of all the items. Due to their self-confidence, students reported having little fear of the English language. When speaking with others, they can quickly demonstrate their degree of language knowledge. This means that their excellent vocabulary knowledge boosts selfconfidence, lowering the sense of fear in the second language. Lucas (2011) states that a good vocabulary mastery allows individuals to command their learning process because it is their comprehension framework. MacIntyre and Gardner (1994) point out that less worried students learn language more easily. As a result, a strong vocabulary predicts a reduced level of anxiety. It demonstrates the ability of the research respondents to communicate using their language knowledge completely, and as English majors, they are relatively confident in this area. A good vocabulary is a steppingstone in relieving anxiety in an English lesson since it unlocks obstacles in understanding input material during the learning process.

Table 7. Reading Competence in Terms of Literal

\begin{tabular}{|c|c|c|c|}
\hline \multicolumn{5}{|c|}{ Prequency } & Percent & Interpretation \\
\hline Scores & 16 & 38.1 & Outstanding \\
\hline 6 & 12 & 28.6 & Very Satisfactory \\
\hline 5 & 14 & 33.3 & Satisfactory \\
\hline $3-4$ & - & - & Dair Satisfactory \\
\hline 2 & - & - & \\
\hline $0-1$ & 42 & 100 & \\
\hline Total & & & \\
\hline
\end{tabular}

Table 7 shows the respondents' degree of reading skill in terms of literal reading comprehension. According to the data, the highest score attained by respondents is 6 , with a frequency of 16 comprising 38.1 percent of the research population. This means that the students' literal level of reading comprehension is outstanding. They can easily use their decoding skills to comprehend the meaning of the texts presented and can be able to read the provided information. They can demonstrate their cognitive abilities in this component of reading comprehension, whichis closely related to an individual's knowledge and understanding. Guided adequately with the knowledge they obtained from the text presented, they can retrieve this information required in the questions and correctly answer the needed information based on the reading material. Combined with their background knowledge and the newly acquired information, most of the learners displayed outstanding skill in the literal level of reading comprehension.

Table 8: Reading Competence in Terms of Interpretative

\begin{tabular}{|c|c|c|c|}
\hline Scores & Frequency & Percent & Interpretation \\
\hline 6 & - & - & Outstanding \\
\hline 5 & 3 & 7.1 & Very Satisfactory \\
\hline $3-4$ & 15 & 35.7 & Satisfactory \\
\hline 2 & 23 & 54.8 & Fair Satisfactory \\
\hline $0-1$ & 1 & 2.4 & Did Not Meet Expectation \\
\hline Total & 42 & 100 & \\
\hline
\end{tabular}


Table 9. Reading Competence in Terms of Applied

\begin{tabular}{|c|c|c|c|}
\hline Scores & Frequency & Percent & Interpretation \\
\hline 8 & 25 & 59.5 & Outstanding \\
\hline $6-7$ & 13 & 31 & Very Satisfactory \\
\hline $4-5$ & 3 & 7.1 & Satisfactory \\
\hline $2-3$ & 1 & 2.4 & Fair Satisfactory \\
\hline $0-1$ & - & - & Did Not Meet Expectation \\
\hline Total & 42 & 100 & \\
\hline
\end{tabular}

Table 8 displays the respondents' level of reading comprehension in terms of interpretative reading. According to the data, the highest response score received by respondents is 2 , with a frequency of 23 constituting 54.8 percent of the research population. This suggests that second-year English major students have a reasonable degree of interpretative reading comprehension. At this level, they are required to read between the lines. The learners could link the clues and texts inside the reading materials and create new knowledge based on the text's evidence. Critical and analytical skills were appropriately employed, and they were able to display a fair satisfactory amount of interpretative reading comprehensi

Table 9 reports the respondents' degree of reading competency regarding the applied level of reading comprehension. According to the data, the top value received by respondents is 8 , with a frequency of 25 encompassing 59.5 percent of the research population. This indicates that the students excel at the applied level of reading comprehension. They are effective at using higher-order cognitive skills. The learner acquires new concepts based on their understanding, insights, and perceptions. The English majors successfully produced their input on the texts based on the information they synthesized. They can flawlessly display their talent in presenting their thoughts and organizing them to properly engage with a query raised based on the given material

Table 10. Writing Competence in Terms of Vocabulary

\begin{tabular}{|c|c|c|c|}
\hline \multicolumn{5}{|c|}{ Frequency } & Percent & Interpretation \\
\hline Mean Score & 10 & 23.8 & Outstanding \\
\hline 5 & 27 & 64.3 & Very Satisfactory \\
\hline 4 & 5 & 11.9 & Satisfactory \\
\hline 3 & - & - & Fair Satisfactory \\
\hline 2 & - & - & Did Not Meet Expectation \\
\hline $0-1$ & 42 & 100 & \\
\hline Total & & & \\
\hline
\end{tabular}

Table 10 shows the English majors' level of writing proficiency in terms of the vocabulary component. According to the data, the highest mean attained by respondents is 4, with a frequency of 27 comprising 64.3 percent of the research population. This means that the pupils' vocabulary component of writing competence is very satisfactory. They demonstrated understanding in concepts that serve as a communicative framework, reflecting in their writing performance. A good vocabulary indicates a significant level of language proficiency as it serves as a framework in language to unlock difficulties. This type of skill can be unlocked by reading a wide range of reading materials. Most research shows that vocabulary can be used at a great advantage since it acts as a key. A wide range of vocabulary enables a learner to quickly comprehend a text, thus increasing the effectiveness of the input material due to their schema present through the utilization of skills in vocabulary. Aside from this, this can also be used in the sense of writing. Such skill can guide a learner to create a written output that is free from repetitions and redundancy. 
English Language Apprehension and the Reading-Writing Competence of Students

Table 11. Writing Competence in Terms of Fluency

\begin{tabular}{|c|c|c|c|}
\hline \multicolumn{5}{|c|}{ Interpretation } \\
\hline Mean Score & Frequency & Percent & Outstanding \\
\hline 5 & 16 & 38.1 & Very Satisfactory \\
\hline 4 & 24 & 57.1 & Satisfactory \\
\hline 3 & 1 & 2.4 & Fair Satisfactory \\
\hline 2 & 1 & 2.4 & Did Not Meet Expectation \\
\hline Total & - & - & \\
\hline
\end{tabular}

Table 11 presents the undergraduates' degree of writing proficiency in terms of the fluency factor. Based on the current data, the highest attained by respondents is 4 , with a frequency of 24 covering 57.1 percent of the research population. This means that the learners' fluency component of writing competence is entirely satisfactory. The second-year English primary student has written language expressed fluidity in the writing process, which is crucial in applying one's thought in the written language. The written outputs are significant in structure and organization. The second-year English majors also displayed an enticing introduction and a satisfying conclusion. This denotes that their writing processes are consistent with the intended purpose and make sense so that the organization of the ideas and thoughts is very satisfactory. Fluidity is essential, especially in writing, since this motivates the reader to read more. A proper organization can support the reader to comprehend the meaning of the reading material thoroughly.

Table 12. Writing Competence in Terms of Grammar

\begin{tabular}{|c|c|c|c|}
\hline Mean Score & Frequency & Percent & Interpretation \\
\hline 5 & 8 & 19 & Outstanding \\
\hline 4 & 14 & 33.3 & Very Satisfactory \\
\hline 3 & 20 & 47.6 & Satisfactory \\
\hline 2 & - & - & Fair Satisfactory \\
\hline $0-1$ & - & - & Did Not Meet Expectation \\
\hline Total & 42 & 100 & \\
\hline
\end{tabular}

Table 12 shows the students' level of writing proficiency in terms of the grammatical category. According to the data, the maximum score received by respondents is 3, with a frequency of 20 comprising 47.6 percent of the research population. This means that the pupils' grammatical component of writing competence is adequate. The English majors demonstrated the skill required in teaching the second language in terms of proper use of tenses, verb inflection based on persons, tenses, and other components. Proficiency in grammar is also vital as they are expected to demonstrate excellent ability in this matter. As future language teachers, the results suggest that they are ready to instruct young language learners. In this regard, proper grammar skills can help them quickly identify the faults in one's language skills since grammar facilitates the language. A good grammar skill indicates the effectiveness of learning and is a significant predictor of language competence. Moreover, as evident from earlier studies, good grammar implies high motivation and self-confidence among learners. If they are aware that they are competent at this component, they can easily display skills in a language such as writing and speaking.

Table 13. Writing Competence in Terms of General Interest

\begin{tabular}{|c|c|c|c|}
\hline \multicolumn{5}{|c|}{ Interpretation } \\
\hline Mean Score & Frequency & Percent & Outstanding \\
\hline 5 & 21 & 50 & Very Satisfactory \\
\hline 4 & 16 & 38.1 & Satisfactory \\
\hline 3 & 4 & 9.5 & Fair Satisfactory \\
\hline 2 & 1 & 2.4 & Did Not Meet Expectation \\
\hline Total & - & - & \\
\hline
\end{tabular}

Table 13 shows the respondents' degree of writing ability in terms of the general interest component. According to the data, the high score received by respondents is 5, with a frequency of 21 comprising 50.0 
percent of the research population. This suggests that the pupils excel in the general interest component of writing competence. The students were able to generate original content, entice the reader, and compose legible text. They concentrated on a single significant concept or topic. This is evident with the ample supporting detail. The objective of their written output is stated concisely and categorically. As inclined with the purpose of sharing their experiences amid the pandemic, the respondents were able to respond correctly, with their original ideas and thoughts put into action.

Table 14. Correlation of English Language Apprehension and Reading-Writing Competence

\begin{tabular}{|c|c|c|c|c|c|c|c|}
\hline & Literal & Interpretative & Applied & Vocabulary & Fluency & Grammar & $\begin{array}{c}\text { General } \\
\text { Interest }\end{array}$ \\
\hline Input Anxiety & .250 & -0.008 & $-0.313^{*}$ & -0.140 & -0.244 & -0.181 & -0.167 \\
\hline Processing Anxiety & 0.144 & -0.020 & -0.293 & -0.224 & $-0.425^{* *}$ & -0.174 & -0.192 \\
\hline Output Anxiety & 0.050 & 0.300 & -0.174 & -0.226 & -0.060 & -0.002 & -0.130 \\
\hline
\end{tabular}

**. Correlation is significant at the 0.01 level (2-tailed).

*. Correlation is significant at the 0.05 level (2-tailed).

The relationship between the respondents' English language apprehension and their reading-writing competence is depicted in Table 14. It indicates a significant association between respondents' apprehension levels and reading-writing proficiency. The results negatively correlated with input anxiety and applied reading comprehension, processing anxiety, and writing fluency. Furthermore, no association exists between input, output, processing anxiety, literal and interpretative reading comprehension levels, vocabulary, grammar, and general interest writing skill components.

These findings are consistent with a broad body of studies on the influence of anxiety on language proficiency. Anxiety is statistically significant and adversely connected with language, as per Alemi et al. (2011), Salehi and Marefat (2014), Teimouri et al. (2019), Lucas et al. (2011), Kabigting and Nanud (2020), and Jugo (2020). It has a devastating effect on output production in all macro skills, making acquisition impossible or more difficult. A high level of anxiety also impacts a learner's accomplishment, remarkably obtaining a better grade or score on an examination. This supports Krashen's (1986) affective filter hypothesis, claiming that language learning will be unsuccessful if the filter is set too high.

In contrast, the input will be more profound and simpler to acquire if set too low. The level of anxiousness is the affective element in this scenario. According to the findings, the higher an individual's level of English language apprehension, the lower or moderate influence on competency is shown.

Argaman and Abu-Rabia (2002), Manoochehr and Behrooznia (2012), and Mohammadpur and Ghafournia (2015) similarly discovered a correlation between anxiety and the student's reading and writing skills. It is also adversely associated and correlates to the findings in other areas of language proficiency, such as those of Mohammadpur and Ghafournia (2015) and Trebits (2014). Anxiety affects language skills in numerous ways. Even though the present study researcher evaluated the student's reading and writing abilities, they reported nervousness in speech. In the Filipino context, Ariola (2011), Macayan et al. (2018), and Jugo (2020) said that most learners are fearful of speaking tasks. As a result, the speaking component of language proficiency must also be investigated. Anxiety appears to be more widespread in speech than in writing, listening, or reading.

This also supports Berowa's (2018) and Jugo's (2020) findings, showing that Filipino learners do not deny anxiety in the second language but maintain a neutral level to promote learning. They are confident in themselves and may only experience modest English language dread due to external stimuli and speaking activities. Kabigting (2020) postulates that neutral anxiety keeps learners motivated and self-confident in understanding input and creating a sound output formulated on their schema and newly gained information. The findings pointed to a negative association between input anxiety and applied reading comprehension. MacIntyre and Gardner (1994) state that a significant level of apprehension at the input process of learning may impair a learner's ability to perform language tasks. In keeping with previous findings, students may be concerned about this component when responding to the question. However, their affective filter is activated because of their surroundings. To generate sound output, the input must be understandable, and the learning 
environment must be encouraging. According to Trebits (2014), input anxiety has both enabling and detrimental effects on learners' output. Students who exhibit high input anxiety levels may be unable to attend to the various verb forms in their input, reducing the correctness of their products because they are expected to communicate their thoughts based on the query asked in the reading text. The higher the input apprehension, the lower the learner's reading comprehension in terms of applied level. In line with earlier findings, this suggests that when an input or an interlocutor delivers their/its message too quickly, a learner experiences a significant amount of apprehension. This affects their reading skills, precisely, their applied level of reading comprehension. It can then be observed that to process an applied level of reading skills and activate higher-order thinking skills in this matter. The environment must be conducive to learning. The input material must be delivered at a pace that the learners are comfortable with. This can be done by analyzing the students' ability through activities that concern skills related to this.

In line with Teimouri's (2019) results, students are frequently free to read a reading material at their own pace, revisit portions of the material that they cannot fully comprehend and utilize additional resources to support comprehension. Furthermore, whereas learners can adjust their performance using the numerous (non)linguistic methods available to them to communicate their gist successfully, they have limited means to decipher an interlocutor's message when misperceptions happen. The idea reinforces the notion that when the environment interrupts the input, the output suffers.

Statistical evidence also shows a negative relationship between processing anxiety and writing fluency. According to MacIntyre and Gardner (1994), excessive anxiety levels during this learning process can impair a learner's capacity to grasp communications or learn new second language skills. According to Macayan (2019), learners are forced to repetitive checking and revising due to the inherent delay in feedback in writing activities, analogous to 'constant grammar corrections.' Unlike her findings, the current study respondents were unable to demonstrate brilliance in terms of writing flow. Anxiety is an issue to consider at this stage, as input processing may have prevented them from making a sound output correctly. The processing stage is concerned with an individual's anxiousness when doing cognitive tasks. Students attempt to organize and save knowledge received from external stimuli. Because it is based on an individual's knowledge extent, the complexity or quantity of learning material predicts apprehension experienced at this process. The learners may have been preoccupied with preserving proper grammatical use, vocabulary application, and building interest, preventing them from constructing a seamless flow in writing. In line with the findings of processing anxiety, learners experience a neutral level when the class seems disorganized. As implied by the results of this research, the learning environment has a crucial role in learning. If a class is too disruptive for the learners, apprehension arises, thus lowering their ability in writing, specifically, fluidity in writing. Fluidity is, therefore, an ability reliant on the environment since grammar, vocabulary, and the ability to draw in readers are more fundamental cognitive processes and can be applied in any manner. If apprehension level arises, fluidity is disrupted.

The findings of this study contradict previous research on the outcomes of distinct anxiety factors on second language ability. According to Trebits (2014), anxiety has a more profound influence on learning than input and processing. Input and processing anxiety are thought to be elements that contribute to anxiety up to the output stage. According to the findings, input and output anxiety are stronger than output anxiety. Furthermore, the anxiety felt at these two levels did not correspond to the pressure felt during the learning process.

The findings also contradict MacIntyre and Gardner's (1994) hypothesis, where apprehension in a second language may influence cognitive processes in a second language. The combined effect of fear produces a negative outcome such as inability to execute and proficiency. Because information is being transmitted, the quality of the previous two phases significantly impacts the last step. The current study found a significant influence of anxiety in earlier cognitive processes such as input and processing. As a result, anxiety is a distinct construct that exists in all mental processes in learning. It is consistent with Piniel's (2012) findings and supports the utility of input, processing, and output scales for evaluating various elements of second language anxiety. They are distinct aspects that influence the learning processes. 


\section{Conclusions:}

During the input stage, learners' level of English language apprehension is neutral. They grow concerned when a stimulus decodes their communication too quickly. Anxiety might arise when a language is spoken too rapidly, and a learner cannot absorb it effectively. Concentration on the input may be difficult, prompting the filter level to rise.

During the processing stage of learning, learners have a neutral level of apprehension. External elements such as social or environmental factors, according to the participants, have a substantial impact on anxiety. Anxiety develops when the English class is disorganized that can cause worry, fear, and dread. This suggests that the learning environment is critical. A positive learning environment fosters second language selfcognition as well. If unaffected, high self-cognition in the processing stages indicates good knowledge quality.

Students expressed moderate levels of output anxiety. According to the data, most learners are nervous in class. They may be afraid of their classmates' or teacher's or professor's corrections. Most Filipino learners, regardless of second language fluency, cannot generate due to environmental factors. They reported feeling frustrated when they attempted to speak English but were unable to convey themselves verbally. This topic may address some underlying issues, such as self-awareness and contextual factors. Unsafe quantities of this component may impair their performance. Anxiety develops from the social presence, and they are terrified of being judged or criticized by their classmates or teachers. Most students strive to make an excellent initial impression, which inhibits their potential to offer higher-quality work.

Literal reading comprehension is strong among the students. They may easily use their decoding abilities to comprehend the gist of the text presented and read the information provided. Students in their second year of English major demonstrated a reasonable level of interpretative reading comprehension. They read between the lines in this component, indicating their critical and analytical ability. At the applied level of reading comprehension, students perform exceedingly well. They are skilled at using higher-order cognitive processes. Learners were able to communicate their opinions in response to the question asked in the reading text.

The vocabulary component of respondents' writing competence is adequate. As evidenced by their writing performance, they demonstrated comprehension of topics that serve as a communicative framework. The fluency component of the student's writing ability is entirely satisfactory. The written output of the respondents demonstrated fluidity in the writing process, which is critical in applying one's thought in written language. The students' writing competence has an adequate grammatical component. The English majors demonstrated the expertise required in teaching the second language regarding the proper use of tenses, verb inflection based on persons, tenses, and other components. The students outperform in the general interest component of writing competency. The participants were able to create original content, engage the reader, and write understandably.

The apprehension of the English language and reading-writing ability are significantly related. Negative correlations exist between input anxiety, processing anxiety, applied level of reading comprehension, and writing fluency. There is no correlation between input, output, processing anxiety, literal and interpretative reading comprehension levels, vocabulary, grammar, and general interest writing skill components.

This research study found a negative link between apprehension in the input stage and applied reading comprehension level. Furthermore, whereas learners can adjust their performance using the numerous (non)linguistic methods available to them to communicate their gist successfully, they have limited means to decipher an interlocutor's message when misperceptions happen. Moreover, writing fluency and processing anxiety are statistically associated. Students may have been preoccupied with preserving good grammar, vocabulary and developing interest, which prevented them from producing a fluid flow.

A moderate lessening effect on applied reading comprehension and writing fluency increases degrees of English language apprehension in input and processing anxiety. Even though the researcher evaluated the students' reading and writing abilities, pupils indicated anxiety when speaking. Most Filipino pupils are terrified of public speaking assignments. As a result, speaking ability must be researched. Speech appears to be more common than writing, listening, or reading. To facilitate learning, Filipino learners maintain a neutral level of stress in the second language. 


\section{Recommendations:}

The discussion of the input materials must be delivered at a rate that the learners can follow. Teachers can develop an interactive learning method online, especially when doing class discussions such as group activities like brainstorming, think, pair and share, buzz session, incident, and Q\&A sessions. This may lessen the students' apprehension in taking the input and possibly strengthen the transfer of information.

The learning environment must be conducive. It can be achieved by reducing possible stressors, disruptors, and distractors in education, such as moving around to notify students of the teacher's presence in face-toface interaction, having a teaching routine for learners to track, or implementing innovative group tasks students are familiar to. Amid the distance learning output, several etiquettes can also be implemented to promote a well-established learning environment. This may lessen apprehension experienced during the processing stage of learning.

The students' anxiety differs from each stage of the learning process. Further research about the said phenomena is recommended, with the dependent variables congruent to each construct to understand the nature of English language apprehension. Future researchers can perform activities corresponding to each construct of anxiety to provide a broader range of more valid data. Since the researcher used only the second-year English major students as the respondents, it is suggested to use all the year levels or explore other majors or select any levels of extremity, either the lowest or highest level.

The researcher used an adapted questionnaire. As indicated in the third chapter, the research questionnaire reached the floor target of reliability. This proves that it can be used in the Philippine context. However, the questionnaire can be improved further. Further testing and research in the Philippine context are recommended.

\section{References:}

[1] Abdelhalim, S. M. (2017). Developing EFL Students' Reading Comprehension and Reading Engagement: Effects of a Proposed Instructional Strategy. Theory and Practice in Language Studies, 7(1), 37. https://doi.org/10.17507/tpls.0701.05

[2] Ahmed, M., (2016). Using Facebook to Develop Grammar Discussion and Writing Skills in English as a Foreign Language for University Students. Sino-US English Teaching, 13(12). https://doi.org/10.17265/1539-8072/2016.12.004

[3] Alemi, M., Daftarifard, P., \& Pashmforoosh, R. (2011, August). The Impact of Language Anxiety and Language Proficiency on WTC in EFL Context. The Sharif University of Technology, Tehran, Iran.

[4] Al-Khasawneha, F. M. (2016). Investigating foreign language learning anxiety: A case of Saudi undergraduate EFL learners. King Khalid University, Abha, Saudi Arabia.

[5] Alsamadani, H. A. (2017). The Effectiveness of Using Online Blogging for Students' Individual and Group Writing. International Education Studies, 11(1), 44. https://doi.org/10.5539/ies.v11n1p44

[6] Alvermann, D. E., \& Phelps. S. F. (2002). Content reading and literacy. Succeeding in today's diverse classrooms. (3rd Ed.). London.

[7] Anggraeny, D., Said, I., \& Febriani, R. B. (2020, January). The EFL Student's Perception of their Foreign Language Anxiety in Speaking Class. Faculty of Teacher Training and Education, Galuh University, Indonesia.

[8] Argaman, O., \& Abu-Rabia, S. (2002, April). The Influence of Language Anxiety on English Reading and Writing Tasks Among Native Hebrew Speakers. The University of Haifa, Haifa, Israel.

[9] Ariola, J. (2011). Language Anxiety in Oral Communication of San Beda College Alabang Staff and Employees. Sam Beda College Alabang, Muntinlupa, Philippines.

[10] Awan, R.-u.-N., Azher, M., Anwar, M. N., \& Naz, A. (2010, November). An Investigation of Foreign Language Classroom Anxiety and Its Relationship with Students' Achievement. University of Sargodha, Pakistan.

[11] Berowa, A. M. (2018, July). Levels of Language Anxiety Toward English: A Sample from Davao del Norte. Mindanao State University, Mindanao, Philippines.

[12] Biria, R., \& Jafari, S. (2013). The Impact of Collaborative Writing on the Writing Fluency of Iranian EFL Learners. Academy Publisher. 
[13] Buac, M., Gross, M., \& Kaushanskaya, M. (2014). The Role of Primary Caregiver Vocabulary Knowledge in the Development of Bilingual Children's Vocabulary Skills (Research Article). Journal of Speech, Language, and Hearing Research.

[14] Camacho, A. C., Loayon, M. M., Loren, M., \& Sabreena, T., Castro D. (2017). Foreign Language Anxiety and Classroom Performance among College Students. ARETE, 5(1), 1-1. Retrieved from https://ejournals.ph/article.php?id=13782

[15] Castellanos, I., Kronenberger, W. G., Beer, J., Henning, S. C., Colson, B. G., \& Pisoni, D. B. (2014). Preschool speech intelligibility and vocabulary skills predict long-term speech and language outcomes following cochlear implantation in early childhood (Research Paper). Cochlear Implants International.

[16] Coşkun, E., Balc1, A., \& Özçakmak, H. (2013). Trends in Writing Education: An Analysis of Postgraduate theses written in Turkey. Procedia - Social and Behavioral Sciences, 93, 1526-1530. doi:10.1016/j.sbspro.2013.10.076

[17] Cristobal, J.-A., Candy, R., \& Lasaten, S. (2018). Oral Communication Apprehensions and Academic Performance of Grade 7 Students. Asia Pacific Journal of Multidisciplinary Research, 6(3), 5-16. Retrieved from http://www.apjmr.com/wp-content/uploads/2018/07/APJMR-2018.6.3.02a.pdf

[18] Daffern, T., Mackenzie, N. M., \& Hemmings, B. (2016). Predictors of writing success: How important are spelling, grammar, and punctuation? (Research Paper). Australian Journal of Education.

[19] EF EPI 2020 - Philippines. (2020). Retrieved July 19, 2021, from https://www.ef.com/wwen/epi/regions/asia/philippines/

[20] Gomari, H., \& Lucas, R. I. (2013, February). Foreign Language Learning Motivation and Anxiety among Iranian Students in the Philippines. De La Salle University, Manila, Philippines.

[21] Hinkel, E. (2013). Research Findings on Teaching Grammar for Academic Writing. English Teaching, 68(4). Retrieved from http://208.106.168.105/downloads/ResearchFindingsGrammar.pdf

[22] Inding, A. L. (2020). Improving Reading Comprehension Skills of Grade Iv Pupils Using Effective Comprehension Strategy Instruction. International Social Science Review, 2(1), 1-1. Retrieved from https://ejournals.ph/article.php?id=15816

[23] International Journal of Humanities and Innovation (IJHI. (2021). View of Measuring students' writing skills using Facebook group application in EFL context. Retrieved August 25, 2021, from Humanistudies.com website: http://www.humanistudies.com/ijhi/article/view/43/41

[24] Javier, D. R. C., \& Jubay Jr, R. P. (2019). Exploring Parent-Teacher Collaboration to Improve Students' Vocabulary Skills: An Action Research (Research Article). IJLLT.

[25] Jones, S., Myhill, D., \& Bailey, T. (2012). Grammar for writing? An investigation of the effects of contextualized grammar teaching on students' writing. Reading and Writing, 26(8), 1241-1263. https://doi.org/10.1007/s11145-012-9416-1

[26] Jugo, R. R. (2020, June). Language Anxiety in Focus: The Case of Filipino Undergraduate Teacher Education Learners. Nueva Ecija University of Science and Technology, Cabanatuan City, Nueva Ecija, Philippines.

[27] Juliet, Ma., Elaine, M., \& Lizetthe, C. (2016). Level of Reading Comprehension of the Education Students. ARETE, 4(1), 1-1. Retrieved from https://ejournals.ph/article.php?id=13762

[28] Kabigting, R. P., \& Nanud, J. A. (2020, July). English Language Classroom Anxiety and Performance of Senior High School Learners. Justino Sevilla High School, Arayat, Pampanga, Philippines.

[29] Kabilan, M. K., Seng, M. K., \& Kee, O. A. (2010). Reader-Text Transaction In-Text Comprehension. Universiti Teknologi MARA, Selangor, Malaysia.

[30] Kent, S., Wanzek, J., Petscher, Y., Al Otaiba, S., \& Kim, Y.-S. (2013). Writing fluency and quality in kindergarten and first grade: the role of attention, reading, transcription, and oral language. Reading and Writing, 27(7), 1163-1188. https://doi.org/10.1007/s11145-013-9480-1

[31] Khoshdel-Niyat, F. (2017, March). The C-Test: A Valid Measure to Test Second Language Proficiency? Islamic Azad University, Mashhad, Iran.

[32] Kırmız1, Ö., \& Kırmız1, G. D. (2015). An Investigation of L2 Learners' Writing Self-Efficacy, Writing Anxiety and Its Causes at Higher Education in Turkey. International Journal of Higher Education, 4(2). https://doi.org/10.5430/ijhe.v4n2p57 
[33] Legac, V. (2012). Foreign Language Anxiety in Different Stages of the FL Learning Process and Achievement in Speaking Skill of Monolingual and Bilingual EFL Learners. University of Zagreb, Croatia.

[34] Liu, M., \& Huang, W. (2010, December). An Exploration of Foreign Language Anxiety and English Learning Motivation. Tsinghua University, Beijing, China..

[35] Lucas, R. I., Miraflores, E., \& Go, D. (2011, July). English Language Learning Anxiety among Foreign Language Learners in the Philippines. De La Salle University, Manila, Philippines.

[36] Lynch, T., \& Anderson, K. (2013). Grammar For Academic Writing. English Language Teaching Centre.

[37] Macayan, J. V., Quinto, E. J., Otsuka, J. C., \& Cueto, A. B. (2018). Influence of Language Learning Anxiety on L2 Speaking and Writing of Filipino Engineering Students. Manila, Philippines.

[38] MacIntyre, P. D., \& Gardner, R. (1994, June). The Subtle Effects of Language Anxiety on Cognitive Processing in the Second Language. Nova Scotia, Canada.

[39] Mahmoud, M. M., \& Latif, A. (2012). What Do We Mean by Writing Fluency and How Can It Be Validly Measured? Oxford University.

[40] Manoochehr, J., \& Behrooznia, S. (2012, April). The Effect of Anxiety on Reading Comprehension among Distance EFL Learners. Islamic Azad University, Mashhad Branch, Iran.

[41] Marsala, C. (2020, May). The Effects of Language Anxiety on Second Language Learners: A Literature Review. University of Mary Washington, Fredericksburg, United States.

[42] Megawati, F., \& Anugerahwati, M. (2012). Comic Strips: A Study On The Teaching Of Writing Narrative Texts To Indonesian EFL Students. TEFLIN Journal, 23(2), 183-205. https://doi.org/10.15639/teflinjournal.v23i2/183-205

[43] Mohammad, T., \& Hazarika, Z. (2016). Difficulties of Learning EFL in KSA: Writing Skills in Context. International Journal of English Linguistics, 6(3), 105. https://doi.org/10.5539/ijel.v6n3p105

[44] Mohammadpur, B., \& Ghafournia, N. (2015, June). An Elaboration on the Effect of Reading Anxiety on Reading Achievement. Islamic Azad University, Neyshabur, Iran.

[45] Myhill, D. A., Jones, S. M., Lines, H., \& Watson, A. (2011). Re-thinking grammar: the impact of embedded grammar teaching on students' writing and students' metalinguistic understanding (Research Paper). Routledge.

[46] Myhill, D., \& Watson, A. (2013). The role of grammar in the writing curriculum: A review of the literature (Research Article). Sage.

[47] Nassif, L. (2018, December). The Relationship of Language Anxiety with Noticing and Oral Production of L2 Forms: A Study of Beginning Learners of Arabic. Williamstown, Massachusetts, United States.

[48] Niitemaa, M.-L., \& Pietilä, P. (2018). Vocabulary Skills and Online Dictionaries: A Study on EFL Learners' Receptive Vocabulary Knowledge and Success in Searching Electronic Sources for Information. Academy Publication.

[49] Oruc, E., \& Demirci, C. (2020). Foreign Language Anxiety and English Language Achievement in Higher Education: The Mediating Role of Student Engagement. Bilecik, Turkey.

[50] Paee, R., \& Misieng, J. (2012, December). Foreign Language Classroom Anxiety Scale: A Comparison of Three Models. University Malaysia Sarawak, Sarawak, Malaysia.

[51] Piniel, K. (2012, October). Structural and comparative evidence for the validity of the Hungarian input, process, and output anxiety scales. Eötvös Loránd University, Budapest, Hungary.

[52] Piniel, K. (2012, October). Structural and Comparative Evidence for the Validity of the Hungarian Input, Process, and Output Anxiety Scales. Eötvös Loránd University, Hungary.

[53] Riswanto, Risnawati, \& Lismayanti, D. (2014). The Effect of Using KWL (Know, Want, Learned) Strategy on EFL Students' Reading Comprehension Achievement. Retrieved from http://citeseerx.ist.psu.edu/viewdoc/download?doi=10.1.1.1062.3444\&rep=rep1\&type=pdf

[54] Robinson, L., \& Feng, J. (2016). Effect of Direct Grammar Instruction on Student Writing Skills. Retrieved from website: https://files.eric.ed.gov/fulltext/ED564336.

[55] Ruddell, M. R. (2001). Teaching content reading and writing. New York: John Wiley \& Sons, Inc. 
[56] Sabbah, S. (2018, February). Anxiety in Learning English as a Second Language at a Tertiary Stage: Causes and Solutions. Community College of Qatar, Qatar, Saudi Arabia.

[57] Sakkir, G. \& Dollah, S. (2019, September 25). Measuring students' writing skills using Facebook group application in EFL context. Retrieved September 4, 2021, from ResearchGate website:

[58] Salehi, M., \& Marefat, F. (2014, May). The Effects of Foreign Language Anxiety and Test Anxiety on Foreign Language Test Performance. Iran.

[59] Sayson, B. B. (2017). Oral English Apprehension and Speech Performance of Grade Eleven Students. Tin-Aw, 1(1), 1-1. Retrieved from https://ejournals.ph/article.php?id=13479

[60] Shanahan, T., \& Lomax, R. G. (1986, April). An Analysis and Comparison of Theoretical Models of Reading-Writing Relationship. Columbus, United States of America.

[61] Sinambela, E., Manik, S., \& Pangaribuan, R. E. (2015). Improving Students' Reading Comprehension Achievement by Using $K-W-L \quad$ Strategy. Retrieved from https://citeseerx.ist.psu.edu/viewdoc/download?doi=10.1.1.832.7343\&rep=rep1\&type=pdf

[62] Tee, M. L., Tee, C. A., Anlacan, J. P., Aligam, K. J. G., Reyes, P. W. C., Kuruchittham, V., \& Ho, R. C. (2020). Psychological impact of COVID-19 pandemic in the Philippines. Journal of Affective Disorders, 277, 379-391. https://doi.org/10.1016/j.jad.2020.08.043

[63] Teimouri, Y., Goetze, J., \& Plonsky, L. (2019, February). Second Language Anxiety and Achievement. Washington, United States of America.

[64] Toba, R., Noor, W. N., \& Sanu, L. O. (2019). The Current Issues of Indonesian EFL Students' Writing Skills: Ability, Problem, and Reason in Writing Comparison and Contrast Essay. Dinamika Ilmu, 19(1), 57-73. https://doi.org/10.21093/di.v19i1.1506.

[65] Trebits, A. (2014, April). Sources of Individual Differences in L2 Narrative Production: The Contribution of Input, Processing, and Output Anxiety. Budapest, Hungary.

[66] Ugsad, M. G. (2017). The Effect of Weblog on the Filipino Learners' Writing Performance. JPAIR Multidisciplinary Research Journal, 27(1), 1-1. Retrieved from https://ejournals.ph/article.php?id=12281

[67] Waes, L. V., \& Leijten, M. (2015). Fluency in Writing: A Multidimensional Perspective on Writing Fluency Applied to L1 and L2. ScienceDirect.Wei, L. (2012). Research Methods in Child Language (A Practical Guide). Blackwell Publishing Ltd.

[68] Yassin, A. A., \& Razak, N. A. (2017, September). Investigating The Relationship Between Foreign Language Anxiety in The Four Skills and Year of Study Among Yemeni University EFL Learners. Centre of Languages and Translation, Ibb University, Yemen. 